\title{
Shaping tourists' wellbeing through guided slow adventures
}

\begin{abstract}
Against the backdrop of the United Nations' Sustainable Development Goal 3, good health and wellbeing, this paper reports on a study that examined how outdoor guides perceive their role in facilitating the psychological wellbeing of tourists who consume slow adventure experiences. These experiences, such as canoeing, stargazing or foraging, are characterised by a slower passage of time, immersion in the natural world and a sense of belonging to small social groups. Grounded in research on wellbeing from a positive psychology perspective, the study utilised semi-structured, in-depth, interviews with ten outdoor adventure guides in the Scottish Highlands and Islands. Following a hermeneutic interpretive approach to analyse the interview transcripts, the findings revealed how perceptions of time, meaningful moments and a sense of togetherness are choreographed by slow adventure guides to shape tourists' psychological wellbeing through immersive guided experiences, ultimately helping tourists to re-establish a much-yearned-for connection with nature. The study adds to tourism, wellbeing and sustainability literature by providing new perspectives on psychological wellbeing through guided slow adventures. In particular the findings contribute to positive tourism, or tourism and positive psychology field of research, by revealing how mindful and eudaimonic visitor experiences are organised by adventure tour guides in natural settings.
\end{abstract}

Keywords: tourist experiences, tour guiding, slow adventure, positive psychology, wellbeing

\section{Introduction}

The world is destabilised, troubled and trembling, with insecurities, risks and hazards embedded in all spheres of human lives (Turner, 2003). This state of the world has brought uncertainties and anxieties that give rise to what Beck (1992) and Giddens (1991) termed a risk society, defined as "a systematic way of dealing with hazards and insecurities induced and introduced by modernisation itself" (Beck, 1992, p. 21). Economies, populations and cultures are seen as nodal points of global processes of endless, uncontrollable flows, a world of social fluids (Turner, 2003). Global disturbances, such as wars, diseases and digital technologies, 
have been transferred and translated into distressed images and altered conditions of the human body (Turner, 2003).

Consequently, stress-related problems have become a global concern (WHO, 2020). The World Health Organisation (2001) envisaged that by 2020, the year of writing this paper, depression and related illnesses would become the largest causes of ill-health. The current Covid-19 pandemic has thrown health and wellbeing issues into sharp relief. In the United Kingdom, for example, the government has stipulated that daily exercise is one of only four reasons that people may leave their homes during 'lockdown' (UK Government, 2020), recognising the need to maintain people's physical as well as psychological wellbeing. Pre-pandemic, human wellbeing and the preservation and improvement of health had already come into focus in global discussions of the sustainable development of humankind (United Nations, 2019). Psychological wellbeing is known to be a strong predictor of people's good health and societal prosperity (Keyes, 2002) and happy and healthy people are claimed to be better able to contribute to the development of their countries; their physical and mental health is seen as a driver, indicator and outcome of sustainable development (UNWTO, 2020).

In recognising the conditions of the contemporary world and the need for ensuring the sustainable future of all human societies, an ambitious global initiative, the 2030 Agenda for Sustainable Development, has been adopted (United Nations, 2020). It represents the cumulative outcome of global efforts to address sustainable development, building on the substantial work undertaken by the UN, governments, NGOs and civil society since the 1992 Earth Summit. Among the 17 Sustainable Development Goals (SDGs) that it posits, the agenda identifies good health and wellbeing (SDG 3) as a prerequisite for and a vital aspect of development. Similarly, through developing the 'Tourism for SDGs platform', the UNWTO (2018) encourages tourism stakeholders to engage in SDG implementation strategies and advance their achievements through various initiatives. Its principal objective is promoting greater engagement of the tourism sector with sustainable development and inviting industry and academia to contribute to building new knowledge on improving people's wellbeing. In this paper we respond to these calls by extending the conversation around human wellbeing, particularly focusing on the benefits that immersive guided experiences in natural environments may engender.

Spending time in nature is not only considered leisure, but also therapy ( $\mathrm{Li}, 2018)$. This has long been emphasised as a means to ease stress, curb anxieties and promote inner calm. Nature has been recommended as a space which heals ill bodies and ill minds, and for its benefits it 
has been considered a great contributor to people's psychological wellbeing and happiness (Hartig, Mitchell, De Vries, \& Frumkin, 2014; Huijbens, 2016). Likewise, in nature-rich destinations, respite, adventure and compensation for alienated, accelerated and digitalised lives are often sought. Nature-based tourism, with particular focus on slow adventure as one of its forms, may in many ways help to cure 'postmodern ailments' by offering spaces for restoration, rejuvenation and relaxation (Farkić \& Taylor, 2019).

This paper specifically focuses on guided slow adventure experiences, developed for tourists who do not primarily seek 'hard adventure', characterised by risk and thrill seeking. Broadly, the concept of slow adventure is considered a way of being in and consuming nature through slower, simplified tourism practices (Varley \& Semple, 2015). Immersive journeys that facilitate an affinity with wild landscapes and are experienced in 'nature's timeframe' (Varley, Huijbens, Taylor \& Laven, 2020) are the qualities that lie at the heart of the slow adventure experience. In this context, the role of the tour guide is crucial. It goes beyond the normative conceptualisation of this profession, offering more hospitable services in order to deliver an ever-more desired sense of comfort, security and wellbeing. This aspect of outdoor guiding, which in many ways transcends technical expertise and services delivery, seems to be the emergent critical inquiry into guiding practices and warrants further attention (Farkić, 2018).

The research study reported here therefore addresses the following question: What is the tour guides' perception of their own role in facilitating tourists' sense of psychological wellbeing? Psychological wellbeing, for the purposes of this paper, is broadly defined to include both hedonic wellbeing (a sense of pleasure and experiences of positive emotions) and eudaimonic wellbeing, characterised by a sense of transformation, personal growth and meaning in life (Filep, Laing \& Csikzentmihalyi, 2016). This philosophical distinction in conceptualising wellbeing is widely accepted in the tourism literature (Pearce, 2009; Nawijn \& Filep, 2016). Thus far, examinations of tourists' psychological wellbeing through guided experiences in the outdoors have focused on adventure sport contexts (Houge Mackenzie \& Kerr, 2017) and spiritual tourist experiences (Parsons, Houge Mackenzie \& Filep, 2019). Here we shift the focus to outdoor guides and explore their experiences of the ways in which they facilitate tourists' psychological wellbeing. In doing so, we aim to extend the knowledge around outdoor guiding practices, taking into account the wellbeing dimensions of slow adventure journeys. Firstly, we bring together ideas on slowness, nature and wellbeing, and discuss the ways in which they together meet in the concept of slow adventure. We then approach the guiding practices within slow adventure from the positive psychology perspective and introduce our 
research study and the methodology behind it. Finally, we outline the study's findings and their implications for guiding practices in particular, and sustainable tourism development in general.

\section{Positioning the research: Sustainability, slowness and wellbeing}

In recognising the need to secure the healthy future of the planet, tourism professionals have taken interest in issues such as gross national happiness, quality of life and sustainable development (Liu, 2003; Bushell, 2009; Schroeder, 2015). The contemporary world has become more mobile, interconnected and fluid, and, despite the expectation that technological change would increase people's free time, the pace of life has only accelerated (Rosa, 2013). In the era of technological advancement, coupled with the increased pace of life and our constant race for meeting deadlines, achieving goals and maintaining productivity, time seems to flow ever faster; people's free time has been devalued, quality of life has been diminished and physical and psychological health has become one of the major concerns. To address this, prescriptions to take short, restorative trips into areas rich in nature have become a leading trend in public health programmes worldwide.

In the past several decades, the tourism industry has made attempts to promote responsible and sustainable travel through development of niche products based on nature, such as ecotourism or wellness tourism. Efforts have been made to deliver high quality tourism experiences and connect tourists with destinations through, for example, spending time in nature and getting entangled with local traditions, whilst at the same time protecting resources in host destinations and communities (Liu, 2003; Koščak \& O’Rourke, 2019). Pulling people to less trafficked, healthier and greener destinations, and slowing down their activities, has become a new ethical consumer trend. An attempt to subvert the 'fast world' and the cult of speed have been embodied in the global slow movement (Honoré, 2004). The concept of slowness maintains its focus on learning how to value and cultivate a sense of time and "restore meaning, authenticity, security or identity to time-deprived subjects" (Parkins, 2004, p. 363). Slow tourism celebrates simple, organic, local, traditional, affective and emotional dimensions of the experiences gained through immersion in the destination and local way of life (Dickinson \& Lumsdon, 2010). Slowing down has been adopted in tourism through developing experiences in remote, rural or natural spaces, as they can offer the qualities that many modern tourists seek, particularly focusing on extending time to savour the experience (Heitmann, Robinson, \& Povey, 2011). 
It has been widely acknowledged that wellbeing may be greatly improved through contact with nature, which has prompted the redesign and development of diverse tourism products based on natural resources (Kelly, 2012; Moscardo, 2009; Puhakka, Pitkanen \& Siikamaki, 2017; Smith \& Diekmann, 2017). Visitation to wild natural environments far from urban centres, such as nature reserves and national parks, espouse preventative rather than curative approaches to personal health management (Smith \& Puczko, 2013). Parks too play an essential role in public health as they are easily accessible and available to people living in urban areas. They not only offer space for sport and leisure, but also contribute to enhancing physical, mental, spiritual, social and environmental health (Croy, Moyle, \& Moyle, 2020; Maller, Townsend, Pryor, Brown \& St Leger, 2006). These positive effects are manifested, for example, in the increase of self-esteem and mood (Kuo \& Sullivan, 2001), ability to concentrate (Van den Berg, Koole, \& van der Wulp, 2003), enhanced happiness (Buckley, 2020) or spiritual empowerment (Curtin, 2009; Humberstone, 2011).

In the realm of outdoor adventure tourism, psychological, physical, and social wellbeing benefits have also gained increased attention (Hanna et al., 2019). To date, however, there have been few studies granting attention to the relationship between wellbeing and adventure tourism practices (Houge Mackenzie \& Hodge, 2019). By way of example, Kulczycki \& Lück's (2009) study suggested that "various components of the adventure tourism experience [...] have the capability to actively contribute not only to health, but also to wellbeing" (p. 176). Houge Mackenzie and Hodge (2019) and Houge Mackenzie and Brymer (2018) highlighted eudaimonic and hedonic experiences in the construction of psychological wellbeing through undertaking adventure sports in nature, although their focus was not on slow adventures.

Beyond tourism, leisure studies and outdoor recreation scholarship have substantially contributed to the knowledge around the health benefits of activities in nature. The health aspects of spending time outdoors have been highlighted, and directly linked to overall human happiness and anxiety reduction (Humberstone, 2015; Martyn \& Brymer, 2016). Scholars have researched the benefits of embodied and non-representational aspects of undertaking physical activities in natural environments (Thorpe, 2004; Thorpe \& Rinehart, 2010; Humberstone, 2011), while works on the political dimensions of the environment in lifestyle, alternative and adventure sports have much relevance in understanding the concept of wellbeing (Mellor \& Shillings, 2010). The concepts of adventure or wilderness therapy also bring some in-depth insights into the health benefits of undertaking activities in natural environments (Gass \& 
Russell, 2012). For example, the Japanese practice of shinrin-yoku, or forest bathing, nicely illustrates the simple act of being in the outdoors, as it encourages nature-based tourists to slow down and take their time in reconnecting with nature (Smith \& Diekmann, 2017). As no studies have examined slow adventure experiences through guides' perspectives, there is value in the application of this perspective to help further understand wellbeing in such contexts.

In expanding the slow adventure concept to include the wellbeing dimension, we build on the idea of slowness (Farkić \& Taylor, 2019) to discuss its role in enhancing tourists' psychological wellbeing through guided slow experiences. Cognizant of the ongoing pandemic at the time of writing this paper caused by Covid-19, it appears timely to discuss issues of human wellbeing and means by which psychological elements of the potential existential crisis may, in part, be addressed. This study therefore aims to explore guided slow adventures to better understand wellbeing outcomes of slow adventure guiding practices.

\section{Slow adventure and outdoor guiding}

Slow adventure is one of the emergent trends in nature-based and peripheral tourism that responds to the call for sustainable development. Inspired by the slow movement and friluftsliv, the Scandinavian philosophy of outdoor life (Gelter, 2000), it has been widely accepted both as a theoretical concept and a tourism product (Varley \& Semple, 2015; Farkić, Taylor \& Bellshaw, 2020). Building on the postulates of slowness, the aim of slow adventure is to introduce consumers to the simplicity of just 'being' in the outdoors - in responsible and ethical ways. Such immersive entanglements with natural environs are generally augmented by a skilled guide, as a crucial element of the experience. Slow adventure offers consumers the luxurious commodity of taking time to dwell in nature, being more mindful and developing a connection with their environment (Sheldon, 2020). It also allows space for disconnection from the stressful and disturbing stimuli by which the modern world is overly saturated (Fullagar, Markwell \& Wilson, 2012). In conceptualising slow adventure, Varley and Semple (2015) introduced its four critical dimensions: time, nature, passage and comfort. Whilst their initial proposition of the concept looked into bodily, temporal and environmental aspects of the journey, it did not directly discuss the possibilities for improving wellbeing. This was addressed by Farkić and Taylor (2019) who suggested that slowing down may improve health and reduce anxieties, stress and depression, particularly in more affluent, digitalised and timedeprived societies. 
In the slow adventure context, the guide's role is crucial. It is their responsibility to interpret, mediate and navigate people through unfamiliar wild spaces and negotiate harsh environments and, more importantly, to keep the group together and provide them with care. Definitions of tour-guiding normally focus on the possession of professional knowledge, and managerial and communication skills (Ap \& Wong, 2001; Weiler \& Black, 2014). However, previous research has showed that it goes beyond the general adventure guide's role as they help to create client value and positive experiences through their instrumental, educational, relational and choreographic practices (Farkić, 2018; Rokenes, Schumann \& Rose, 2015). On multi-day trips in particular, accommodating and managing group activities transcends solely technical competency. Their behaviour goes beyond the delivery of services as per script, to include softer, more hospitable acts, which are seen as an amalgam of hospitable service skills and personality traits (Pantelidis, 2014; Varley, Farkić \& Carnicelli, 2018).

The social dimension of guiding practices is paramount to comprehending slow adventures. Slow adventure tours normally gather a small number of participants, thus, social involvement and building esprit de corps within the group is crucial. Natural environments provide space for more intimate social interaction and building social ties, as well as for engendering community identity (Rantala \& Puhakka, 2019). This not only ties the group together but also enhances tourists' immersion in and understandings of the immediate cultural landscapes (Hansen \& Mossberg, 2017). While professionalism in service delivery is often seen as a formal behaviour, or a code of conduct, informality is considered immediate, relaxed, friendly and unofficial behaviour which may permit more meaningful social interactions to unfold and allow for wellbeing possibilities. A guide's professionalism encompasses both service skills and creating pleasant atmospheres in which clients feel cosy, and which allow for social intimacy (Ap \& Wong, 2001). This is one way that guides demonstrate their 'withness': their egalitarianism and engagement with the group (Pyyhtinen, 2016). Such convivial ambience, prompted by guides, fosters togetherness, belonging, sharing and intimacy, all being qualities that imbue a sense of communitas, comfort and wellbeing in shared social spaces, indoors and out (Sharpe, 2005; Varley et al., 2018). Acknowledging the multitude of roles that the outdoor guides are already enacting, it seems appropriate to explore how they perceive their role in facilitating the psychological wellbeing of tourists. 


\section{Approach to wellbeing}

While the concept of wellbeing is far from new, its links with guiding practices are recent (Houge Mackenzie \& Brymer, 2018). In general, wellbeing is considered a holistic concept encompassing temporary feelings as well as long-term contentment (Sheldon \& Bushell, 2009; Smith \& Puczko, 2013). Psychological wellbeing however is viewed as not only the absence of mental disorder and ill-health, but also the presence of positive psychological states, including both hedonic and eudaimonic aspects (Sin \& Lyubomirsky, 2009). The paper adopts this positive psychological conception of psychological wellbeing. The modern foundations of positive psychology have been linked to the humanistic psychology of the late twentieth century, especially to the works of Maslow, Rogers, Murray, Allport and May on selfactualisation, optimal functioning and the good life (Seligman \& Csikszentmihalyi 2000). Positive psychology - the study of what makes life worth living - has been precisely defined as an area of study that aims to emphasise the role of positive emotions, character strengths, and positive institutions in building human well-being and happiness (Seligman \& Csikszentmihalyi, 2000). Despite the early humanistic psychology roots however, modern positive psychology has taken on a distinctly positivist research perspective. It has been criticised for scientism - the belief that the positivist paradigm and the scientific method is the only trustworthy approach to examine happiness, well-being, and flourishing (Durston, 2015). Another major challenge of mainstream positive psychology is that it traditionally includes a positive-only focus, one that is based on binary or dichotomous thinking. In reality, the positives and negatives often cannot be that easily separated and they commonly co-exist in various combinations as shown in the phenomenon of covalence (Lomas, 2016).

Taking into account these criticisms of the mainstream positive psychology, tourism and positive psychology scholarship has developed over the last decade, sometimes simply labelled as positive tourism (Filep et al., 2016). The studies in this field have been described by Ryan (2015, p. 195) as works where "psychometrics are generally absent." In this way, the tourism research on positive psychology avoids methodolotry, the idea of privileging quantitative over qualitative and vice versa (Friedman 2003), unlike mainstream positive psychology. While both mainstream positive psychology and positive tourism conceptualise psychological wellbeing in hedonic and eudaimonic terms, the tourism studies de-emphasize the strict positive-negative dichotomy. It is recognised that tourist experiences (including slow adventures) may sometimes induce wellbeing involving challenges (akin to eudaimonia), as well as pleasurable or hedonic wellbeing (Filep \& Deery, 2010). Varley and Semple (2015), 
for example, explained that extended immersion activities, like those in slow adventures, may be felt as a deep sense of creative accomplishment. At the same time, they recognised that slow adventure activities are characterized by hedonic wellbeing. Furthermore, they involve a degree of challenge which requires stepping out of one's comfort zone (Houge Mackenzie \& Brymer, 2018). There is also evidence that spending extended time in nature, combined with relaxation of the mind, boosts positive emotions. In a study using a positive psychology perspective, Filep, Cao, Jiang and deLacy (2013) examined how tourists reminisce about, or retrospectively savour, their outdoor holiday experiences. Emotions of joy, interest and contentment were most commonly linked to experiences that involved observations of natural scenery, strengthening the importance of spending time in nature. Partaking in activities, such as cooking foraged foods or telling stories around a campfire, gives tourists the opportunity to immerse themselves into prolonged interactions between self and the world, and subsequently reminisce and savour their experiences (Varley \& Semple, 2015). Therefore, the positive tourism approach to wellbeing adopted in this paper is one that incorporates an appreciation of pleasant feelings and positive emotions (hedonic wellbeing) as well as meaningful but often challenging activities (eudaimonic wellbeing).

In the slow adventure context, undertaking activities is not constrained by time but rather conditioned by natural rhythms: changes of dark and light, fluctuations of the water's surface, or the direction of the wind. Getting to know natural rhythms and discovering new ecospheres, landscapes and inhabitants along the journey may be a solipsistic venture; however guided experiences can in many ways make the difference. Consuming such experiences may lead to both hedonic and eudaimonic outcomes, and to the deepening and rounding of the outdoor experience.

\section{Methodology}

\section{Method and participants}

Approaching psychological wellbeing as a human-constructed quality, the research was entirely inductive (Rantala \& Puhakka, 2019), which assumed the researcher's embodiment in the research setting to collect the data. The empirical material presented in this paper draws on semi-structured in-depth interviews conducted with ten outdoor guides between June and August 2016 in the Scottish Highlands and Islands. Interviews were conducted post-tours, and 
were favoured as a non-standardised method as they allowed for flexibility in the direction of the conversation (Evans \& Jones, 2011). They nonetheless proved invaluable as they rendered insights from the different epistemological positions of the informants and gave voice to those who are on the front line, facilitating and co-creating the outdoor experience.

We adopted a phenomenological approach as we were interested in understanding, description and interpretation of subjective human experiences. In phenomenological explorations informants are selected because they have had a lived experience of the phenomenon under investigation (van Manen, 1990). Therefore, those informants who were most likely to provide relevant information were targeted, and their voices are heard in this paper. The recruitment of informants occurred during the tours in which the first author had previously taken part as a paying tourist/researcher and during the guide training courses she had attended. The first author eventually chose to interview ten qualified guides who had extensive experience in guiding slow adventures, trips involving hiking, canoeing and sea kayaking for example. They also developed and delivered a range of guide training programmes based on customer care and improving the customer journey. Most of them had the highest coaching qualifications in scientific and commercial diving, as well as commercial skippering, by which their competence and expertise was accredited. Some of them had experience of leading expeditions or operations management, while others were professional underwater photographers and filmmakers; some also taught as university lecturers.

Through in-depth interviews with these experts, knowledge was gained about their cultural background, personal lives, clients, anecdotes from previous tours, and, most importantly, their personal guiding experiences. During the interviews, the questions were broad and designed to avoid influencing the respondents' answers in any way, and were continually adjusted according to the flow of conversation. Substantive literature preceding the interviews had been taken into account, but attempts were made to avoid prior theoretical assumptions as much as possible in line with our qualitative approach (Connell \& Lowe, 1997). A large corpus of data was eventually generated, consisting of the verbatim transcription of the semi-structured interviews. Each finding inevitably had agency in layering, shaping and constructing the knowledge around lived experiences of guiding in the outdoors.

\section{The approach and interpretation of interview transcripts}


The goal of phenomenological research is to grasp people's experiences and their reflections on them to understand deeper meanings or the significance that such an experience has on an aspect of human life (Smith, 2007). The analytical approach taken in this study was justifiably phenomenological in nature. Heidegger's influence in shaping interpretive phenomenological research is widely recognised and utilised in social sciences (Horrigan-Kelly, Millar \& Dowling, 2016). His phenomenological philosophy influenced the development of interpretive phenomenological research methods that facilitate description and understanding of the human lived experience as well as uncovering its underlying meanings. Heidegger's (2010 [1927]) hermeneutic method, which he called existential understanding, was thus helpful in facilitating the interpretation of lived experiences of our respondents during the interview process, thus situating them in the wider social context. Utilising this method, we were able to envision the whole based on the individual experiences of participants in question, which are always related, depend on each other and are therefore interpreted in a metaphorically circular way.

In the post-fieldwork period, literature was intensively consulted, with the aim of discovering new theoretical insights that arose from the data. Intuitive coding, germane to interpretive phenomenological studies, was used to highlight the emerging themes. The phenomenological approach does not have step-by-step analytic requirements (van Manen, 1990); thus, the codes were allowed to gradually filter and become more powerful than the others through the process of reflection and sensemaking. Our intention, however, was to show how the informants framed their own lived experiences of guiding. The first author interpreted the findings in relation to the broader theoretical discourses on slow adventure, psychological wellbeing and sustainability. The participants reported their guiding practices based on post-experiential reflections and perceptions of the ways in which they contributed to tourists' psychological wellbeing. In this paper we have included those responses that we felt had most relevance to the scope of this study. Initials of the guides' names (e.g. DT) were used in order to adhere to institutional ethical guidelines, as the guides did not consent for their identities to be publicly disclosed.

It is important to mention the researchers' positionalities, as they affect how our previous experiences influenced the framing of this study (Ateljevic, Harris, Wilson, \& Collins, 2005). The first author undertook the doctoral research into tourists' experiences and guiding practices on commercial outdoor tours on which this paper is based. The second author has been developing an international research platform on the wellbeing of tourism stakeholders, with a recent emphasis on the wellbeing of tour guides. The third author has been involved in the 
development of slow adventure since its inception as a marketing concept, applying its ethos and basic tenets to the development of slow adventure experiences across Europe's northern periphery. The three authors, each from their own perspective, have critically interrogated slow adventure's potential to sustainably contribute to human wellbeing through guided experiences in the outdoors. Granting attention to the outdoor guides, we now turn to discuss our findings.

\section{Findings and discussion}

In the discussion that follows we illustrate how the guides reported on tourists' sense of wellbeing through their performances and practices, undertaking activities at a slower pace and facilitating tourists' inward journeys. The section discusses three key themes that emerged from the interview findings: quality time, as a predominantly hedonic wellbeing theme, and two principally eudaimonic themes: flourishing through meaningful moments and a sense of togetherness.

\section{Quality time: chronos versus kairos}

The participants highlighted the potential for slow adventure to contribute to slowing down the passage of time and allow tourists to savour experiences in wild nature. The importance of slowing down and taking time to savour moments is widely linked to positive psychological outcomes of greater wellbeing and mindfulness (Boniwell \& Zimbardo, 2004). The conditions that allowed for the connection with the natural environments, based on the participants' accounts, were the time tourists spent away from everyday life, and the time that was used for enjoyment, unwinding, reflecting and relinquishing. Here the participants referred to hedonic aspects of tourist wellbeing. The chronos/kairos time binary illustrates the significance of spending quality time through slow appreciation of experiences. Chronos expresses a measure, a quantity of duration, whilst kairos is more qualitative in nature and has a special temporal position. It signals a significant event that happens at 'that' time, which could not happen at any other time, and cannot recur (Smith, 1969). It is the kairological time of a slow adventure journey which renders it pleasurable and can help explain the hedonic aspects of being on slow adventure holiday.

Arguably, in the artificially imposed passage of time, measured by the modern clock, people cannot fully realise their authentic being and thus drive themselves into alienation from the self, and from others (Heidegger, 2010 [1927]). This is deeply rooted in people's busy, structured everydayness that some find difficult to disconnect from, even for a short time. 
Partaking in unfamiliar activities in wild nature was not that simple for some participants. It required making an effort to unlearn the daily routine, adapt to a new setting and learn new skills, which for some were strange and uncommon practices, as one guide opined:

I've had two males that couldn't cope with that [being in the outdoors]. It is funny because they wanted, the ones that I struggled with were very high achieving, very affluent males, Western males, whose lives were programmed, well planned, you know, high performance at work, and the relationships, every minute is filled, someone who is hard to say 'hey, chill out, listen to the bird song', they were like (looking at the watch) for how long, for how long? [...] They are just not used to closing their mind a little bit. (DT)

As the guides explained, for these participants it was particularly difficult to exchange the discomfort of being in and going slowly through the outdoors for the familiarity of busyness. In such situations, the guides would aim to navigate tourists through space, encouraging them to disconnect from their inherent adherence to 'chronos' and embrace the kairotic moment:

At times I make the point of shutting up, you know, especially at beaches and nice places, and I will actually say 'look guys, how about you just go find a nice space, take lunch, just go and live it, you don't need me to tell you how beautiful it is, just go and absorb it, sit on the sand, look at the sky, realise that this is a unique moment in time that's yours so go and enjoy it and let's meet again in half an hour or whatever'. (DT) The guides played a vital role in delicately facilitating and choreographing tourists' experiences, rendering them more immersive by connecting tourists with the place, navigating their movements and actions, and making them take time to savour the experience. Here, time was perceived as something subjective, as opposed to measurable, linear passage controlled by the clock. Kairological moments, even if mediated, were deeply appreciated by participants and felt as a true sense of enjoyment and pleasure. In describing the ways in which they facilitated their clients' connection with the place, one guide explained:

When you see what people view on the beach or on a lonely place, you just tell a story that people used to live there, then there's a point in it, there's a silence, people are kind of computing it, reflecting on it. (EO)

An extension of this role sees the slow adventure guide subtly engineering and engendering a form of respect for the surroundings (Sheldon, 2020), a personal stewardship over the 
landscape. For this to occur, extended time spent in the natural environment is vital, which this guide recognised and confirmed:

I help create the experience and it definitely is interpreting what they are seeing and enhancing it. 'Coz I think if I am looking at the outcome, I would like to see people enjoying what they are experiencing, and understand it, and even more so, develop some kind of relationship with it... some kind of responsibility, if they kind of want to protect it or even just go and find out more. (EO)

Slowing down to belong to the moment, and make a connection with the place or with others, or even allow for small inward journeys and deep reflections, accounted for imaginative processes of framing and recounting the experience (Semple, 2013). This kairological time added value in the hearts and minds of participants, thus deepening their conveyance of hedonic feelings.

This is what slow adventure ultimately strives to achieve, in accord with Szerszynski's (2002) explanation that "we also typically experience kairological time not just as a succession of meaningful moments, but as narratively organised into story-like wholes at various scales" (p. 183). Lived experiences interpreted through the lens of kairological time were mediated and heightened by the guides' interaction with the group: they facilitated tourists' pleasure through, for example, orchestrating the encounters with wildlife and otherworldly landscapes, evoking memories and telling stories around a crackling campfire. Such encounters facilitated an 'emotional engagement' with the guide, increasing situational consciousness and decreasing the client's chronotic awareness (Pearce, 2020). It is 'just then' when the slow passage of time allowed people's marginal selves to dominate and reframe more hedonic experiences, before they re-entered the structure of their everyday realities.

\section{Flourishing through meaningful slow moments}

Another important theme that has been uncovered in the findings is the state of flourishing which was achieved through mediating, constructing and living meaningful moments during tours. The physical and mental space that tourists came to occupy (according to the guides), was in fact the ethos of slow adventure - it worked to encourage reducing stress-related conditions and anxieties imposed by busy, structured lives, and at the same time fostered responsible and sustainable behaviour in wild nature. The guides sought to teach the group how to temporarily forget their long to-do lists and permanently busy lives, allowing them to not 
only better understand the natural world, but also what makes them fulfilled and enables their own psychological wellbeing. In these out-of-the-ordinary moments, clients were more predisposed to relax and feel a sense of freedom, epiphanies and deep spiritual connections with the place. Such meaningful moments, which were often described as transformative by the participants, formed the essence and fabric of the slow adventure experience. Guides played a key co-creational role as 'change-makers' (Sheldon, 2020), facilitating potentially lifechanging, flourishing effects (Pritchard, Morgan, \& Ateljevic, 2011). While it may seem that renewal of the self was highly individual, such deeply meaningful spiritual experiences were perhaps triggered by the presence of other participants, or the guide:

It was a van talk with a lady who's actually an extremely high-flying psychoanalyst, she lived in Hollywood and she dealt with a lot of celebrities, she never divulged who everybody was but you know, she was obviously very high-flying, she was actually reduced to tears when we were talking just about life, about personal things and about losses. I suffered loss, and she had a personal thing that happened to her, but we weren't answering each other's questions, we were just talking and all of the sudden I became aware she was crying, you know. I was driving, and it was difficult. I just put my hand on her knee, you know, just this connection, you know, we were in it together, we understand and afterwards, she was doing this laughing-crying thing... (EO)

This opening-up and letting-go was a manifestation of Bauman's (2013) assertion that "for us in particular - who happen to live in ruthless times, [...] the word 'community' sounds sweet." (pp. 2-3). Another guide reflected more generally on the perceived impact of these experiences on their clients' inner-gaze:

Working in the adventure travel industry really made me realise that we are changing lives, we do make a difference.... So people are having life changing experiences when they are spending time with you, when they are on holidays, when they have time to ponder, when they have time to chill out and actually look at their lives and see what's not quite right. So that's my favourite kind of experience, getting that sort of feedback from people saying like 'listen, thank you for providing me with the space and the possibility to, yeah, change my life and to have these kind of moments that will be with me for ever'. (SL)

The guides demonstrated awareness of the meaningful contributions that they were making. Their presence and empathy largely contributed to transformation of the self, a sense of comfort, self-fulfilment, happiness and overall psychological wellbeing. In achieving this, the 
guide's role was to contextualise and approach each 'client' individually, which aligned with the newest trends in global wellness provision (Global Wellness Summit, 2020). This finding builds on previous research that explained how guides facilitated their clients' sense of flourishing through spiritual tourist experiences (Parsons et al., 2019). The guide adopted the spiritual advisor role, guiding clients towards insight and enlightenment (Cohen, 1985), as well as facilitating their inner journey, brokering their flourishing, and ultimately enabling their eudaimonic wellbeing (Weiler \& Black, 2014; Parsons et al., 2019).

\section{Sense of togetherness in slow adventure experiences}

A sense of togetherness was the third major findings theme. The tourists, according to the guides, generally valued the comfortable feeling of immersion in the place: entangled with the sound of splashing waves, the smell of seaweed scattered on the rocky ocean coast, or making that connection with the traditions of the land. Varley's (2011) explanation that "participants enjoy membership of vibrant, immediate (yet temporary) Dionysiac communities, immersed in a lived critique of routinised everyday life" (p. 87) has much relevance to the interpretation of the group's outdoor experience. Here we can turn to Turner's (1974) notion of communitas to interpret the social aspect of guided experience, as through meaningful sharing of time and space, personal stories, experiences and memories this vital quality occurred. A sense of togetherness gradually emerged, creating equality and fellowship, resulting in friendships:

And we just laughed, almost for seven days, with clients, they were such a nice group, but very early on the whole group just gelled, just something kind of happened and everybody just became the closest of friends. [...] At this meal in the evening, after a great day we've been up in the corries, in the Cullins, so everybody was on a high, and ready to just let go a bit and the food was good and they had wine and they loved my stories... [...] It was just a great, uplifting period, I don't know, it was just very special. (EO)

These socialities signified one of slow adventure's vital dimensions, as they greatly contributed to tourists' feelings of belongingness, fulfilment and overall wellbeing. Guides created familiar, communal spaces in which social capital was generated: pleasurable moments of having a laugh, making friends, sharing a drink. These shared experiences created "a state of pleasant wellbeing and security, with a relaxed frame of mind and open enjoyment of the immediate situation in all its small pleasures" (Hansen, 1976, p. 54; cf. Varley et al., 2018). 
Slow adventure experiences are most often co-constructed with fellow sojourners as people naturally focus on ‘being-with' other people (Veijola, Molz, Pyyhtinen, Höckert, \& Grit, 2014). This was true for both tourists and the guides:

I've had some very deep times with people, which I think have been lovely and it kind of connected us as humans. [...] With some I had some really deep times, we made really good friends, I just can't help it. It is a shame when it comes to the end of the week and you have to say bye. (LS)

This communal effervescence (Turner, 1974) was felt by the guides to unfurl naturally with the shared experience of sitting around a campfire after a day of outdoor activity. When the body was tired but the mind still alert, when everyone was unwinding and content with the day's challenges, discoveries and achievements, it was easy to fall into what the guide described as 'deep times': emotionally-charged collective joy and exaltation. Such communal moments strengthened emotions by "bringing all those who share them into more intimate and more dynamic relationship" (Olaveson, 2001, p. 100). The feeling of comfortable, communal belonging, even temporary and subtly orchestrated by the skilful guide, had the potential to endure in the memory of the participants.

The slow adventure experiences, based on the guides' accounts, therefore created opportunities for creating pleasant and inclusive atmospheres, communitas possibilities at the heart of an outdoor experience. The guided journeys entailed elements of simplicity and togetherness, post-prandial sharing of intimate spaces and atmospheres, and stories that were told in small social circles and convivial environments. Frequent social interactions among the group members broke down the imagined distance, built trust among them and allowed for deeper, more meaningful moments. This eudaimonic quality enabled by the guides, and the consequent emotional stability, engendered a certain sense of ontological security and wellbeing whilst consuming slow adventure experiences.

\section{Conclusion}

We have presented and discussed the ways in which guided slow adventures can offer possibilities to increase psychological wellbeing through slow journeying in nature. The creative time spent outdoors, whether actively doing or simply being, has taken on heightened significance as Covid-19 threatens to impose a new reality. Our conceptualisation of adventure took a broader view, away from risk and thrill towards a definition encompassing slower 
activities (Rantala, Rokenes, \& Valkonen, 2016) such as foraging, stargazing, or simply being still in time and space, savouring the outdoor experience. The study showed provision of these guided slow adventures using wild and unfettered landscapes promoted, enabled and delivered greater psychological wellbeing. In a modest way, these choreographed slow adventure tours contributed to Sustainable Development Goal 3, good health and wellbeing. Through navigation of slow adventure experiences, guides enhanced wellbeing by engaging tourists in immersive activities, extending time, securing comfort and deepening their multisensorial engagement with surrounding places and social groups. Ultimately, these experiences have the potential to, even temporarily, slow down the tempo and alter perceptions of time, a challenge in a culture of deadlines and expeditious achievements (Humberstone, 2015).

The study aimed to give voice to the guides to explore their own perceptions of the ways in which they facilitated hedonic and eudaimonic states among tourists. Whilst tourists' perspectives were beyond the scope of the study, the perspectives of those on the front line of service delivery were useful in illustrating the ways in which a sense of wellbeing was constructed in slow adventures. To that end, each set of the empirical findings worked towards deepening understanding of the guide's practices to deliver a sense of security, comfort, homeliness and wellbeing during commercial outdoor tours (Varley et al., 2018). Firstly, the findings supported the assertion that for slow tourism experiences to be felt and lived, they often need to be mediated by the guides. Through slow, immersive consumption of experiences, the disconnection between modern, affluent consumers and wild nature may partly be overcome. Secondly, the findings highlighted the guide's role as a spiritual advisor and a steward (Parsons et al., 2019), a person who has the power, in some way, to enact meaningful moments in tourists, and in this way contribute to their flourishing; although we cannot speculate on the durability of this effect. Lastly, the findings illuminated the significance of the social aspect of slow adventures, and the role of the guide in enhancing the sense of togetherness and belonging during tours, even if the participants had hitherto been mere strangers. The illustrative quotes ultimately aimed to convey the message that slow adventure guides may minimise tourists' anxieties and uncertainties and maximise their sense of security and psychological wellbeing.

Theoretically, we hope the paper contributes to tourism, wellbeing and sustainability studies by illuminating the existential aspects of being on holiday and the ways in which slow adventures can make a meaningful change in the lives of tourists. In offering novel ways to approach studying human wellbeing, the findings highlight the relevance of quality, 
kairological, time and slowness in tourism. In this way, the study responds to calls within positive tourism research (Filep \& Laing, 2019; Filep et al., 2016) for fresh investigations of mindful and eudaimonic visitor experiences. In the future, wellness tourism researchers may extend the research into tourists' wellbeing through examining the consumption of wellness products and mediated experiences delivered in outdoor settings (Bushell, 2009). This also creates space for further research into guiding practices, as well as into wellbeing of tour guides, particularly inviting cross-disciplinary dialogues as well as novel, disruptive and creative methodologies in their explorations.

Lastly, new understandings revealed by participants in our study may open up new avenues for developing guiding training programmes that include elements that foster clients' wellbeing. The development and professionalisation of the tourism workforce are continual and highly contextualised processes (Baum, Kralj, Robinson \& Solnet, 2016). While there appears to be a healthy demand for experiences that incorporate or focus on wellbeing in nature via slow adventures (Varley \& Semple, 2015), the challenges remain in terms of human capital, creating guides who have the requisite skillset, ethos, care and desire. The lack of tourists' insights is a limitation of this study. Future research could complement the findings by exploring the experiences of guided slow adventure journeys from the tourist perspective and interrogating their perceived wellbeing in relation to guiding practices.

Allowing an expert to guide clients through an alien environment, enabling them to enjoy the haptic, olfactory, auditory or visual phenomena - be it the sound of splashing waves, the explosion of colours in the golden hour or the crackling of the campfire - may, briefly restore tourists' peace of mind. In uncertain times after Covid-19, being slow and mindful might alleviate some of the people's anxieties and fears. In slow adventure environments, guides can foster longed-for feelings of reconnection, restoration, reunion or regeneration, and make a modest, but a meaningful contribution to the psychological wellbeing of the troubled inhabitants of the 21 st century.

\section{References}

Ap, J., \& Wong, K. K. (2001). Case study on tour guiding: Professionalism, issues and problems. Tourism Management, 22(5), 551-563.

Ateljevic, I., Harris, C., Wilson, E., \& Collins, F. L. (2005). Getting 'entangled': Reflexivity and the 'critical turn'in tourism studies. Tourism Recreation Research, 30(2), 9-21. 
Bates, W. (2009). Gross national happiness. Asian-Pacific Economic Literature, 23(2), 1-16.

Baum, T., Kralj, A., Robinson, R. N., \& Solnet, D. J. (2016). Tourism workforce research: A review, taxonomy and agenda. Annals of Tourism Research, 60, 1-22.

Bauman, Z. (2013). Community: Seeking safety in an insecure world. New York, NY: John Wiley \& Sons.

Beck, U. (1992). From industrial society to the risk society: Questions of survival, social structure and ecological enlightenment, Theory, Culture \& Society, 9(1), 97-123.

Bell, S., Tyrväinen, L., Sievänen, T., Pröbstl, U., \& Simpson, M. (2007). Outdoor recreation and nature tourism: A European perspective. Living Reviews in Landscape Research, 1(2), 146.

Boniwell, I., \& Zimbardo, P. G. (2004). Balancing time perspective in pursuit of optimal functioning. Positive Psychology in Practice, 12, 141-155.

Brymer, E., Cuddihy, T. F., \& Sharma-Brymer, V. (2010). The role of nature-based experiences in the development and maintenance of wellness. Asia-Pacific Journal of Health, Sport and Physical Education, 1(2), 21-27.

Buckley, R. (2020). Nature tourism and mental health: Parks, happiness, and causation. Journal of Sustainable Tourism, 28(9), 1409-1424.

Bushell, R. (2009). Quality of life, tourism, and wellness. Wellness and tourism: Mind, body, spirit, place. Putnam Valley, NY: Cognizant Communication, 19-36.

Castanier, C., Scanff, C. L., \& Woodman, T. (2010). Who takes risks in high-risk sports? A typological personality approach. Research Quarterly for Exercise and Sport, 81(4), 478-484.

Cohen, E. (1985). The tourist guide: The origins, structure and dynamics of a role, Annals of Tourism Research, 12(1), 5-29.

Connell, J., \& Lowe, A. (1997). Generating grounded theory from qualitative data: The application of inductive methods in tourism and hospitality management research. Progress in Tourism and Hospitality Research, 3(2), 165-173.

Croy, W. G., Moyle, B. D., \& Moyle, C. L. J. (2020). Perceived benefits of parks: The roles of information source exposure and park use. Journal of Sustainable Tourism, 1-20.

Curtin, S. (2009). Wildlife tourism: The intangible, psychological benefits of human-wildlife encounters. Current Issues Tourism, 12, 451-474.

Dickinson, J., \& Lumsdon, L. (2010). Slow travel and tourism. London: Earthscan.

Dodds, R., \& Butler, R. (Eds.). (2019). Overtourism: Issues, realities and solutions (Vol. 1). Berlin: Walter de Gruyter GmbH \& Co KG. 
Durston, K. (2015).The corrupting influence of scientism. Evolution News and Views. Available at: http://www.evolutionnews.org/2015/08/the corrupting098371.html (accessed on 20 February 2020).

Evans, J., \& Jones, P. (2011). The walking interview: Methodology, mobility and place. Applied Geography, 31(2), 849-858.

Farkić, J. (2018). Outdoor guiding as hospitality work. Annals of Tourism Research, 73(C), 197-199.

Farkić, J., \& Taylor, S. (2019). Rethinking Tourist Wellbeing through the Concept of Slow Adventure. Sports, 7(8), 190.

Farkić, J. Taylor, S., \& Bellshaw, S. (2019). Slow adventure in rural and peripheral areas. In Ethical and Responsible Tourism (Marko Koščak and Tony O'Rourke, Eds.). New York, NY: Routledge, 83-95.

Filep, S. (2009). Tourists' happiness through the lens of positive psychology (Doctoral dissertation). Townsville, QLD: James Cook University.

Filep, S., Cao, D., Jiang, M., \& DeLacy, T. (2013). Savouring tourist experiences after a holiday. Leisure/Loisir, 37(3), 191-203.

Filep, S., \& Deery, M. (2010). Towards a picture of tourists' happiness. Tourism Analysis, 15(4), 399-410.

Filep, S., \& Laing, J. (2019). Trends and directions in tourism and positive psychology. Journal of Travel Research, 58(3), 343-354.

Filep, S., Laing, J., \& Csikszentmihalyi, M. (2016). What is positive tourism? Why do we need it?. In Positive Tourism (Sebastian Filep, Jennifer Laing and Mihaly Csikszentmihalyi, Eds.). New York, NY: Routledge, 17-30.

Friedman, H. (2003). Methodolatry and Graphicacy. American Psychologist 58 (10), 817-18.

Fullagar, S., Markwell, K. \& Wilson, E. (2012). Starting slow: Thinking through slow mobilities and experiences. In Slow Tourism: Experiences and Mobilities; (Simone Fullagar, Kevin Markwell and Erica Wilson, Eds.). Bristol, UK: Channel View Publications, 1-8.

Gass, M.A.; Gillis, H. L.; \& Russell, K. (2012). Adventure therapy: Theory, practice, \& research. New York, NY: Routledge.

Gelter, H. (2000). Friluftsliv: The Scandinavian philosophy of outdoor life. Canadian Journal of Environmental Education, 5(1), 77-92.

Giddens, A. (1991). Modernity and Self-identity: Self and Society in the Late Modern Age, Stanford, CA: Stanford University Press. 
Global Wellness Summit (2020). Global Wellness Trends. Available at: https://www.globalwellnesssummit.com/global-wellness-trends-2/ (accessed on 28 April 2020).

Hansen, J. F. (1976). The Proxemics of Danish Daily Life. Studies in the Anthropology of Visual Communications, 3(1), 52-62.

Hansen, A. H., \& Mossberg, L. (2017). Tour guides' performance and tourists' immersion: facilitating consumer immersion by performing a guide plus role. Scandinavian Journal of Hospitality and Tourism, 17(3), 259-278.

Hanna, P., Wijesinghe, S., Paliatsos, I., Walker, C., Adams, M., \& Kimbu, A. (2019). Active engagement with nature: outdoor adventure tourism, sustainability and wellbeing. Journal of Sustainable Tourism, 27(9), 1355-1373.

Hartig, T., Mitchell, R., De Vries, S., \& Frumkin, H. (2014). Nature and health. Annual Review of Public Health, 35, 207-228.

Heidegger, M. (2010 [1962]). Being and Time. Albany, NY: Suny Press. [Originally published in German, in 1927].

Heitmann, S., Robinson, P., \& Povey, G. (2011). Slow food, slow cities and slow tourism. In Research Themes for Tourism (Peter Robinson, Sine Heitmann, and Peter Dieke, Eds), Oxford, UK: CABI, 114-127.

Honoré, C. (2004). In Praise of Slowness: Challenging the Cult of Speed. Sydney, NSW: Harper Collins Publishers.

Horrigan-Kelly, M., Millar, M., \& Dowling, M. (2016). Understanding the key tenets of Heidegger's philosophy for interpretive phenomenological research. International Journal of Qualitative Methods, 15(1), 1609406916680634.

Houge Mackenzie, S., \& Brymer, E. (2018). Conceptualizing adventurous nature sport: A positive psychology perspective. Annals of Leisure Research, 23(1), 79-91.

Houge Mackenzie, S., \& Hodge, K. (2019). Adventure recreation and subjective well-being: A conceptual framework. Leisure Studies, 1-15.

Houge Mackenzie, S., \& Kerr, J. H. (2017). Positive motivational experience over a threeday outdoor adventure trek in Peru. Journal of Adventure Education and Outdoor Learning, 17(1), 4-17.

Huang, X., Huang, Z., \& Wyer Jr, R. S. (2016). Slowing down in the good old days: The effect of nostalgia on consumer patience. Journal of Consumer Research, 43(3), 372-387.

Huijbens, E.H. (2016). Rhythmic revitalisations. In The Routledge Handbook of Health Tourism (Melanie Kay Smith and László Puczko, Eds.). New York, NY: Routledge, 365-374.

Humberstone, B. (2011). Embodiment and social and environmental action in nature-based sport: Spiritual spaces. Leisure Studies, 30(4), 495-512. 
Humberstone, B. (2015). Embodiment, nature and wellbeing: More Than the Senses? In Experiencing the outdoors (Margaret Robertson, Ruth Lawrence and Gregory Heath. Eds.). Boston, MA: Springer, 61-72.

Kelly, C. (2012). Wellness tourism: Retreat visitor motivations and experiences. Tourism Recreation Research, 37(3), 205-213.

Keyes, C. L. (2002). The mental health continuum: From languishing to flourishing in life. Journal of Health and Social Behavior, 207-222.

Koščak, M. \& O'Rourke, A. (2019). Ethical and Responsible Tourism. New York, NY: Routledge.

Kulczycki, C., \& Lück, M. (2009). Outdoor adventure tourism, wellness, and place attachment. In Wellness and Tourism: Mind, Body, Spirit, Place (Cory Kulczycki and Michael Lück, Eds.). New York, NY: Cognizant Communication Corporation, 165-176.

Kundera, M. (1995). Testaments Betrayed: An essay in Nine Parts. Sydney, NSW: Harper Collins.

Kuo, F. E., \& Sullivan, W. C. (2001). Environment and crime in the inner city: Does vegetation reduce crime?. Environment and Behavior, 33(3), 343-367.

Li, Q. (2018). Shinrin-yoku: The Art and Science of Forest Bathing. London: Penguin.

Liu, Z. (2003). Sustainable tourism development: A critique. Journal of Sustainable Tourism, $11(6), 459-475$.

Lomas, T. (2016). Flourishing as a dialectical balance: Emerging insights from second-wave positive psychology. Palgrave Communications, 2(1), 1-5.

Maller, C., Townsend, M., Pryor, A., Brown, P., \& St Leger, L. (2006). Healthy nature healthy people: 'contact with nature' as an upstream health promotion intervention for populations. Health Promotion International, 21(1), 45-54.

Mansfield, L., Daykin, N. \& Tess, K. (2020). Leisure and wellbeing, Leisure Studies, 39:1, 110.

Martyn, P., \& Brymer, E. (2016). The relationship between nature relatedness and anxiety. Journal of Health Psychology, 21(7), 1436-1445.

Matteucci, X., \& Filep, S. (2017). Eudaimonic tourist experiences: The case of flamenco. Leisure Studies, 36(1), 39-52.

Mellor, P.A., \& Shillings, C. (2010). Body pedagogics and the religious habitus: A new direction for the sociological study of religion. Religion, 40 ,27-38. 
Moscardo, G. (2009). Tourism and quality of life: Towards a more critical approach. Tourism and Hospitality Research, 9(2), 159-170.

Nawijn, J., \& Filep, S. (2016). Two directions for future tourist well-being research. Annals of Tourism Research, 61, 221-223.

Olaveson, T. (2001). Collective effervescence and communitas: Processual models of ritual and society in Emile Durkheim and Victor Turner. Dialectical Anthropology, 26(2), 89-124.

Pantelidis, I.S. (2014). The Routledge Handbook of Hospitality Management. New York, NY: Routledge.

Parsons, H., Houge Mackenzie, S., \& Filep, S. (2019). Facilitating self-development: how tour guides broker spiritual tourist experiences. Tourism Recreation Research, 44(2), 141152.

Parkins, W. (2004). Out of time: Fast subjects and slow living. Time \& Society, 13(2-3), 363382.

Pearce, P. L. (2009). The relationship between positive psychology and tourist behavior studies. Tourism Analysis, 14(1), 37-48.

Pearce, P.L. (2020). Tourists' perception of time: Directions for design, Annals of Tourism Research, 83, 102932.

Pritchard, A., Morgan, N., \& Ateljevic, I. (2011). Hopeful tourism: A new transformative perspective. Annals of Tourism Research, 38(3), 941-963.

Puhakka, R., Pitkänen, K., \& Siikamäki, P. (2017). The health and well-being impacts of protected areas in Finland. Journal of Sustainable Tourism, 25(12), 1830-1847.

Pyyhtinen, O. (2016). More-than-human sociology: A new sociological imagination. New York, NY: Springer.

Rantala, O., \& Puhakka, R. (2019). Engaging with nature: nature affords well-being for families and young people in Finland. Children's Geographies, 1-14.

Rantala, O., Rokenes, A., \& Valkonen, J. (2016). Is adventure tourism a coherent concept? A review of research approaches on adventure tourism. Annals of Leisure Research, 21(5), 539552.

Rokenes, A., Schumann, S., \& Rose, J. (2015). The art of guiding in nature-based adventure tourism-how guides can create client value and positive experiences on mountain bike and backcountry ski tours. Scandinavian Journal of Hospitality and Tourism, 15(sup1), 62-82.

Rosa, H. (2013). Social Acceleration: A New Theory of Modernity. New York, NY: Columbia University Press.

Ryan, C. (2015). Book Review: Tourist Experience and Fulfilment: Insights from Positive Psychology. Annals of Tourism Research, 52:195-96. 
Seligman, M. \& Csikszentmihalyi, M. (2000). Positive Psychology: An Introduction. American Psychologist, 55 (1): 5-14.

Schroeder, K. (2015). Cultural values and sustainable tourism governance in Bhutan. Sustainability, 7(12), 16616-16630.

Semple, T. (2013). The semiotics of slow adventure: Narrative and identity. In Adventure Tourism (Steve Taylor, Peter Varley and Tony Johnston, Eds.). New York, NY: Routledge, 77-90.

Sharpe, E. (2005). Delivering communitas: Wilderness adventure and the making of Community, Journal of Leisure Research, 37(3), pp. 255-281.

Sheldon, P. J. (2020). Designing tourism experiences for inner transformation. Annals of Tourism Research, 83, 102935.

Sheldon, P. J., \& Bushell, R. (2009). Introduction to wellness and tourism. In Wellness and tourism: Mind, body, spirit, place (Robyn Bushell and Pauline J. Sheldon, Eds). New York, NY: Cognizant Communication, 3-18.

Sin, N. L., \& Lyubomirsky, S. (2009). Enhancing well-being and alleviating depressive symptoms with positive psychology interventions: A practice-friendly meta-analysis. Journal of Clinical Psychology, 65(5), 467-487.

Slow Adventure in Northern Territories (2019). Available at http://www.interregnpa.eu/projects/funded-projects/project/148/ (accessed on 12 December 2019).

Smith, J. A. (2007). Hermeneutics, human sciences and health: Linking theory and practice. International Journal of Qualitative Studies on Health and Well-being, 2(1), 3-11.

Smith, J. E. (1969). Time, times, and the 'right time'; Chronos and Kairos. The Monist, 53(1), $1-13$.

Smith, M. K., \& Diekmann, A. (2017). Tourism and wellbeing. Annals of Tourism Research, 66, 1-13.

Smith, M., \& Puczkó, L. (2013). Health and Wellness Tourism. New York, NY: Routledge.

Szerszynski, B. (2002). Wild times and domesticated times: the temporalities of environmental lifestyles and politics. Landscape and Urban planning, 61(2-4), 181-191.

Thorpe, H. (2004). Embodied boarders, snowboarding status \& style. Waikato Journal of Education, 10, 181-201.

Thorpe, H., \& Rinehart, R. (2010). Alternative sport and affect: Non-representational theory examined. Sport in Society, 13 (7/8), 1268-1291.

Turner, B. S. (2003). Social fluids: Metaphors and meanings of society. Body \& Society, 9(1), 1-10. 
Turner, V. (1974). Dramas, fields, and metaphors: Action in human society. Ithaca, NY: Cornell University Press.

Tourism for SDGs. (2020). Available at: http://tourism4sdgs.org/unwto/ (accessed on 20 April 2020).

United Kingdom Government (2020). Coronavirus outbreak FAQs: What you can and can't do. Available at: https://www.gov.uk/government/publications/coronavirus-outbreak-faqswhat-you-can-and-cant-do/coronavirus-outbreak-faqs-what-you-can-and-cant-do (accessed on 25 April 2020).

United Nations (2020). Sustainable Development Goals. Available at: https://www.un.org (accessed on 17 October 2019).

van den Berg, A.E., Koole, S.L., \& van der Wulp, N.Y. (2003). Environmental preference and restoration: (How) are they related? Journal of Environmental Psychology, 23, 135-146.

Van Manen, M. (1990). Researching lived experience: Human sciences for an action sensitive pedagogy. London, ON: Althouse.

Varley, P. J. (2011). Sea kayakers at the margins: the liminoid character of contemporary adventures. Leisure Studies, 30(1), 85-98.

Varley, P., Farkić, J., \& Carnicelli, S. (2018). Hospitality in wild places. Hospitality \& Society, 8(2), 137-157.

Varley, P., \& Semple, T. (2015). Nordic slow adventure: Explorations in time and nature. Scandinavian Journal of Hospitality and Tourism, 15(1-2), 73-90.

Varley, P.J., Huijbens, E.H., Taylor, S., \& Laven, D. (2020). Slow adventure: from natural concept to consumer desire. Östersund : Mid Sweden University (Rapportserien / European Tourism Research Institute 2020:2.

Veijola, S., Molz, J. G., Pyyhtinen, O., Höckert, E., \& Grit, A. (2014). Introduction: Alternative tourism ontologies. In Disruptive Tourism and its Untidy Guests (Soile Veijola, Jennie Germann Molz, Olli Pyyhtinen, Emily Hockert and Alexander Grit, Eds.), Basingstoke, UK: Palgrave Macmillan, 1-18.

Veenhoven, R. (2008). Sociological theories of subjective well-being. The Science of Subjective Well-being, 9, 44-61.

Weiler, B., \& Black, R. (2014). Tour guiding research: Insights, issues and implications. Bristol, UK: Channel View Publications.

Willig, C. (2008). A Phenomenological Investigation of the Experience of Taking Part in Extreme Sports'. Journal of Health Psychology, 13(5), 690-702.

Woodman, T., MacGregor, A. L., \& Hardy, L. (2019). Risk can be good for self-esteem: beyond self-determination theory. Journal of Risk Research, 1-13. 
World Health Organization (2020). Depression. Available at: https://www.who.int/newsroom/fact-sheets/detail/depression (accessed on 1 February 2020).

World Health Organization (2020). Mental health action plan 2013 - 2020.. Available at: https://www.who.int/mental_health/publications/action_plan/en/ (accessed on 13 January 2020).

World Tourism Organization (2018). Tourism and the Sustainable Development Goals Journey to 2030. Available at: https://www.e-unwto.org/doi/pdf/10.18111/9789284419401 (accessed on 8 February 2020). 